\title{
The influence of children's gender on parents' happiness
}

\author{
Jin $\operatorname{Han}^{1, a}$, ZHANG LIYANG ${ }^{2, b,{ }^{*}}$ \\ ${ }^{1}$ Sichuan province, Chengdu City, Chenghua District, Chengdu university of technology, China \\ ${ }^{2}$ No.331 Pinyuan 3 Building, No.59 Zhongguancun Street, Haidian District, Beijing, China \\ a1003519736@qq.com, b18811311646@163.com \\ ${ }^{*}$ Corresponding author
}

Keywords: Children's gender, happiness, differences, influence

\begin{abstract}
Now more and more people say that the happiness of the parents who give birth to boys are not as good as the daughters. Especially between the ages of 24 and 30, the happiness of the boys' parents is significantly lower than that of the girls' parents. The higher the house price, the lower the happiness of the boy's parents. As far as the pressure of life is concerned, the family of sons born in today's society is much larger than the family of daughters. The most central issue is the house. Parents who have sons have to face this problem from the birth of their children. In the process, the quality of life is affected, which will definitely lower the happiness of parents. Just a few decades ago, the happiness of the sons and daughters was overwhelming over the daughters, including some rural areas. The reason is that in some people's minds, the son is the hope of succession, and the only hope after the parents are old. Under the influence of this concept, in the past, whoever gave birth to a son is bound to be happy, and the happiness of parents is bursting. This essay analyzes the influence of children's gender on parents' happiness in three aspects: the influence of children's marital stability on children's marital stability, the influence of children's costs and benefits in the marriage market, and the influence of children's and children's happiness on parents.
\end{abstract}

\section{Introduction}

Short video app Douyin is becoming more and more popular in China, where people upload various interesting short videos. Two of the fathers sat together to eat, the plate in front of one father was filled with crabs, while the other , was carrots on the plate. People ridiculed: "What is your monthly salary?" The former replied: "3000", the latter replied: "10000", the man asked again, why the three thousand eat so well, but the monthly salary of 10,000 eat carrots, the person who eats crabs smiled and said proudly: "I have a daughter." The latter cried : "I have two sons." In fact, such an example is not uncommon. Many netizens said that when they gave birth to a son, they immediately began to save money in order to buy a house for their son. However, they gave birth to a daughter will plan to buy a new car for themselves. In the traditional concept, more Chinese families want to have sons. However, today more and more people say that the pressure on raising a boy is too high, and that raising a girl is to be happier. This topic has caused extensive discussion among scholars and netizens. Is it good to have a boy or a girl? Is it still necessary to use the traditional concept of "respecting the patriarchal" and "cultivating the child to prevent the elderly"? Have the daughter will be happier? This article explores and discusses this topic. In a society like China that has a long tradition of farming civilization and long-standing existence of the concept of "patriarchal patriarchalism", does the gender difference in children and how it affects parents' happiness?

\section{Literature Review}

Becker(1960\&1973) believes that the increase or decrease of family members follows the law of diminishing marginal returns, and the income of monogamous families from new members is diminishing. On this basis, monogamy is the most efficient form of marriage, and he has gained a dominant position in the form of marriage. 1 
After analyzing the marriage market, Becker studied fertility behavior. Unlike traditional theories, Becker sees the family not only as a consumer but also as a production unit. He believes that children are actually the most important "products" of the family.

The raising of children as family products is to pay the cost, that is to say, the child's production and parenting are also an investment behavior. This kind of investment is divided into two parts: economic input and emotional input. The economic input can include direct cost and indirect costs two parts. Direct costs are expenses for food, clothing, entertainment, and learning. Indirect costs, also known as opportunity costs, refer to the opportunities that parents lose for raising children or the income from using them. For example, raising children to sacrifice their parents' leisure time, pregnancy or raising children may affect their mother's promotion or even lose their jobs.

Happiness as a "hidden national wealth" (David Halpern, 2012) has received increasing attention worldwide. The problems mentioned above have largely become the factors influencing parents' acquisition of happiness. However, the different genders of children also have a great influence on the acquisition of parents' happiness.

\section{The impact on the stability of parents' marriage}

China's traditional culture and social customs have negatively opposed divorce since ancient times. In traditional culture, the purpose of marriage is not for the love and happiness of both men and women, but for the "raising the next generation" (Zeng Yi, 195). Childbearing or raising offspring is one of the intrinsic purposes of traditional Chinese marriage.3 In China, especially in relatively occluded rural areas, mothers who can have boys are considered to be "capable" people. At home, they have the right to say and higher status; mothers, who give birth to girls, are considered to be "incapable", have no right to speak at home and low status, may even be discriminated against. Not only that, but the particularity of Chinese society is also manifested in China as a country with strong boy preference. On the basis of these two aspects, the boy is more helpful to pass on the family and help parents achieve the goal of raising children and supporting them when they getting old. Under the condition that the country strictly limits the number of family births, the fact that the wife does not have a child born may be an important factor in causing the couple's contradictions. Therefore, after the boy is born, the parents will pay more attention to the child. On the one hand, for the fathers, there are successors who can continue the future generations. In the future, they will be looked after properly. On the other hand, compared with the girl, the mother's credit is greater. On the "credit", this marriage will be more treasured by the man. On the contrary, if a daughter is born, the chance of divorce will increase as the mother does not have a boy to give birth to a husband who can breed a violent successor. Simply put, boys are more conducive to the stability of their parents' marriage than girls.

\section{The impact of costs and interests on the marriage market}

First, the difference in cost of parenting has different effects. In traditional Chinese customs, parents have the obligation to make a son a family. They must pay for their son to find a spouse. This may be a gift, or it may include repairing their own house, buying durable consumer goods, and various costs before marriage. 4All of these costs add up is not a small fee. Although there are differences in parental expenses, the economic burden is what parents with sons must bear. Even after the son had a family, in the eyes of the traditional Chinese, the son is a self-family, so after the son just got married, he may need some labor or economic subsidies, and some parents also bear this responsibility. In comparison, the daughter does not have this problem. Raising a daughter hardly has to worry about her daughter's family problems. Most of these costs are borne by the man, and even a gift can be obtained. Although it is necessary to pay for the cost of the dowry, it should not necessarily exceed the income from the man. In the process of raising daughters, the daughters of some families may receive less education, especially when the economy is relatively tight and cannot support more children at the same time. At this time, the unmarried daughter will provide free services for the 
family, or go out to earn income. Subsidize the family to ease the burden on parents. In general, in terms of cost, parents who raise their sons have to pay more, and raising their daughters will pay less. Second, expect differences to bring about differences in happiness. Based on the above, parents pay more for their sons, and sons must also take on more obligations, especially in the aspect of pension. It is because of the expectation given to the son that the sons are part of the expectation, and failure to do so will damage the sense of well-being. But the daughter is different. There is no expectation and requirement for the daughter to have no obligation in this respect. If the daughter is not good enough, then she can accept it. She did not have these obligations. If the daughter is good to her parents, then this is an unexpected surprise that can greatly enhance the happiness. In some interviews, it was found that many elderly people, while ill, even though they thought that their daughters would provide care and help, they were positioned as "helping", while parents and public opinion were "responsible" for their sons. Therefore, the difference between the son and the daughter in the role will lead to differences in the expectations and requirements of the parents. This difference will lead to a greater promotion of the parents' happiness.

\section{Differences in happiness brought about by natural differences in gender}

Differences in happiness brought about by natural differences in gender. Men and women have some natural trait differences, which leads to different effects and behaviors in their interactions with people. From the perspective of willingness and actual behavior, some foreign studies have found that daughters may be more filial than sons. They are more willing to take care of their elderly parents, and daughters are better than daughters in-laws.5 However, the son-in-law's level of respect for the in-laws of the parents and daughter-in-law is similar. The daughter and her parents have more intimate relationships and family ties than their sons, providing more social support, and having a daughter can give the elderly more phone calls or a chance to visit relatives at the daughter's house, which helps to improve happiness. Compared with sons, daughters and mothers are more intimate, mothers and daughters are better than sons, they will be more willing to discuss problems with their daughters and seek help. These have led to significant differences in the influence of daughters and sons on parental well-being, that is, in terms of the natural differences in gender, the daughter brings a stronger sense of happiness to the parents.

\section{Conclusion}

Based on the three points of the above study, make a summary. First, compared with girls, the boy Parent's marriage is more stable and the parent's happiness is higher. Affected by long-standing traditional ideas, the status of boys is higher than that of girls, because boys are more conducive to the succession of the family, helping parents achieve the goal of raising children and supporting them, couples are more inclined to have boys. This state is more pronounced in relatively occluded rural areas. Second, in terms of the comparison of benefits and costs in the marriage market, the happiness of the boys' parents is lower than the happiness of the girls. This is because the high price of the bride makes the boy's parents feel pressured and prepares for the marriage when the boys are born. But in fact, the pressure to buy a wedding house is different for different families. If the boy's family's economic strength is good, this pressure may be low or even non-existent. Moreover, as the concept of newly-married love is gradually accepted, more and more young men and women are buying wedding houses together, and such differences may be narrowed. Finally, the gender of boys and girls also has a certain impact on the happiness of parents. The study found that parents who gave birth to girls had higher self-esteem than parents who gave birth to boys.

Other studies have shown that happiness is not only affected by economic factors such as income and price, but also by multiple factors such as age, gender, education level, and environmental health. Therefore, we cannot simply equate the gender of the child with the happiness of the parents. 


\section{References}

[1] Becker, Gary, 1960, “An Economic Analysis of Fertility”, Demographic and Economic Change in Developed Countries, Princeton University Press, 1960, 209—240.

[2] Camerer, Colin, 2003, Behavioral Game Theory: Experiments in Strategic Interaction, Princeton University Press.

[3] Chen, X. , 2014, Gender Imbalance and Parental Substance Use In Rural China, Working Paper.

[4] Ebenstein, A. , 2010, “The 'Missing Girls' of China and the Unintended Consequences of the One Child Policy” ,Journal of Human Resources, Vol.45, 87-11.

[5] Edlund, L. , H. Li, J. Yi, and J. Zhang, 2013 , “Sex Ratios and Crime: Evidence from China” , Review of Economics and Statistics, Vol.95, 1520-1534.

[6] Ferrer-i-Carbonell, Ada, and Paul Frijters, 2014, “How Important is Methodology for the Estimates of the Determinants of Happiness?” , Economic Journal, 114 ( 497) : 641-659.

[7] Levinson, A. 2012, "Valuing Public Goods Using Happiness Data: The Case of Air Quality" , Journal of Public Economics, Vol.96,869-880.

[8] Li, L., and X. Wu, 2011, "Gender of Children, Bargaining Power, and Intrahousehold Resource Allocation in China” , Journal of Human Resource, Vol. 46, 295-316.

[9] Luechinger, S. , and P. Raschky, 2009, “Valuing Flood Disasters Using the Life Satisfaction Approach” , Journal of Public Economics, Vol. 93, 620-633.

[10]Mishkin, Frederic S. , 2007, “Will Monetary Policy Become More of a Science? ” ,NBER Working Paper, No. 13566. 